\title{
PROPOSITION OF A LEAN FLOW OF PROCESSES BASED ON THE CONCEPT OF PROCESS MAPPING FOR A BUBALINOCULTURA BASED DAIRY
}

\section{Gislei Leonel de Faria ${ }^{1}$, Jhennifer Tulik ${ }^{2}$, Marcelo Carneiro Gonçalves ${ }^{3}$}

${ }^{1}$ Acadêmica do curso de graduação em Engenharia de Produção no Centro Universitário Campos de Andrade - Uniandrade. Curitiba - PR. Brasil.

${ }^{2}$ Acadêmica do curso de graduação em Engenharia de Produção no Centro Universitário Campos de Andrade - Uniandrade. Curitiba - PR. Brasil.

${ }^{3}$ Professor do curso de graduação em Engenharia de Produção no Centro Universitário Campos de Andrade - Uniandrade. Curitiba - PR. Brasil.

Email: gisleileonel5@gmail.com,jhennifer.tulik@gmail.com, marcelo.ccbn@ hotmail.com

Received: April 17th, 2019

Accepted: May 17th, 2019

Published: June $30^{\text {th }}, 2019$

Copyright $(02016$ by authors and Institute of Technology Galileo of Amazon (ITEGAM). This work is licensed under the Creative Commons Attribution International License (CC BY 4.0). https://creativecommons.org/lice nses/by/4.0/

\begin{abstract}
The exploration of bubalinocultura in small farms shows itself as an important instrument of social progress, resulting in benefits for small producers and their activities, bringing an opportunity for growth and development for them. The article aims to present the proposal of a flow of processes for a company characterized as an artisan dairy, producing buffalo cheeses, using as process analysis tool the process mapping, in order to present the benefits and improvements that this tool can provide. Thus, data were collected from the production process through information transmitted through company employees and participant observation. The process mapping, through a process diagram, allowed an amplified view of the production of buffalo cheese, where it is possible to analyze the step by step of the productive activities and the respective time of completion of each of them. As a result, it is possible to draw up an improvement plan through corrections of some activities, reducing cycle time and developing more efficient and effective processes.
\end{abstract}

Keywords:Bubalinocultura, Buffalo Cheese, Production Management, Process Mapping.

\section{PROPOSIÇÃO DE UM FLUXO ENXUTO DE PROCESSOS COM BASE NO CONCEITO DE MAPEAMENTO DE PROCESSOS PARA UMA QUEIJARIA BASEADA NA BUBALINOCULTURA}

\section{RESUMO}

A exploração da bubalinocultura em pequenas propriedades mostra-se como importante instrumento de progresso social, acarretando em benefícios para os pequenos produtores e suas atividades, trazendo oportunidade de crescimento e desenvolvimento para os mesmos. O artigo objetiva apresentar a proposta de um fluxo enxuto de processos para uma empresa caracterizada como uma queijaria artesanal, produtora de queijos de búfala, utilizando como ferramenta de análise do processo produtivo o mapeamento de processos, a fim de apresentar os benefícios e melhorias que esta ferramenta pode proporcionar. Assim, foram coletados dados do processo produtivo através de informações transmitidas por meio dos funcionários da empresa e observação no processo in loco. A realização do mapeamento de processos, através de um diagrama de processos, possibilitou uma visão amplificada da produção de queijo de búfala, onde é possível analisar o passo a passo das atividades produtivas e o respectivo tempo de conclusão de cada uma delas. Como resultado, é possível traçar um plano de melhoria por meio de correções de algumas atividades, proporcionando a redução do Lead Time das atividades e o desenvolvimento de processos mais eficientes e eficazes.

Palavras-Chave: Bubalinocultura, Queijo de Búfala, Gestão da Produção, Mapeamento de Processos. 


\section{INTRODUÇÃO}

Segundo [1] o rebanho bubalino apresentou nos últimos anos uma taxa de crescimento de $45 \%$. No estado do Paraná a bubalinocultura pode ser considerada um nicho de mercado, pois a prática de suas atividades na região é pouco explorada. Porém, ela vem destacando-se devido à rusticidade dos búfalos que tem facilidade em adaptar-se a todos os ambientes, facilitando o manejo e ordenha e, conseqüentemente, podendo se tornar uma das atividades mais promissoras no setor de economia pecuária.

Realizando um estudo em uma queijaria artesanal, localizada na cidade de Rio Branco do Sul, no estado do Paraná, com a abordagem no setor bubalino, mais precisamente a produção de leite e seus derivados, neste caso, o queijo, tem-se a oportunidade de propor a aplicação de técnica de gestão da produção, possibilitando melhorias nos processos produtivos de sua exploração em pequenas propriedades rurais.

Deste modo, o objetivo geral deste artigo tem como finalidade propor um fluxo de processos baseando-se no conceito de mapeamento de processos, no processo produtivo de queijo de búfala de uma queijaria artesanal.

O estudo visa planejar e melhorar os processos na produção de queijo de búfala, visto que sua exploração em pequenas propriedades mostra-se como importante instrumento de progresso social, pois os pequenos produtores adquirem ganhos substanciais em suas atividades, tendo assim a oportunidade de crescimento e desenvolvimento, além de proporcionar aos consumidores um produto de excelente qualidade.

Com a proposta de mapeamento de processos é possível obter uma significativa redução no lead time do processo e oportunidade de desenvolvimento de práticas enxutas na empresa.

O presente artigo se estrutura da seguinte maneira: Na seção 1 é apresentada a introdução, na qual ocorre a exposição do assunto abordado; Na seção 2 é apresentada a metodologia de pesquisa utilizada; Na seção 3 é exposta a revisão bibliográfica da pesquisa; $\mathrm{Na}$ seção 4 temos a exposição dos resultados; Na seção 5 são expostas as considerações finais e logo após são citadas as referências.

\section{REFERENCIAL TEÓRICO}

\section{II.1 A BUBALINOCULTURA NA REALIDADE BRASILEIRA}

Conforme [5] os búfalos foram inseridos no Brasil no final do século XIX, originários da Ásia. Inicialmente a intenção de trazê-los ao país era em razão de substituírem o rebanho bovino em regiões nas quais os bovinos, devido as suas características, não conseguiam se desenvolver. Esse advento era chamado de "vazio pecuário" e, assim, os búfalos viriam para fazer a ocupação desses vazios. No entanto, devido a sua rusticidade e fácil adaptabilidade a qualquer ambiente, os bubalinos foram ganhando espaço na pecuária brasileira com taxa de crescimento expandindo-se a cada ano.

Segundo dados da [1] o rebanho bubalino hoje é de, aproximadamente, 3 milhões de animais. Se comparado com o rebanho bovino nos dias de hoje, 150 milhões, representa $2 \%$ desse rebanho. "Os búfalos são animais domésticos da família dos bovídeos, de origem asiática, utilizados para produzir carne e leite para consumo humano". [1].

Conforme dados do [6], atualizados em 13 de março de 2018, o estado do Paraná aparece na $8^{\mathrm{a}}$ colocação em relação à população de bubalinos no ano de 2017 , com número de animais equivalente a 32.253. Nesse cenário no qual foi apresentado o rebanho bubalino de todos os estados brasileiros, os que lideram o ranking é o estado do Pará, Amapá e São Paulo, com 514.308, 286.477 e 102.922 animais cada respectivamente.

\section{II.2 A IMPORTÂNCIA DO QUEIJO DE BÚFALA}

Para [7] ressaltam a importância da bubalinocultura na pecuária brasileira através da produção de leite. A produção e comercialização dos derivados do leite de búfala, destacando-se o queijo tipo mozarela e a ricotta, fazem com que o país tenha uma expansão de mercado neste ramo, o mesmo está se desenvolvendo por meio da crescente procura por tais produtos que possuem excelentes qualidades nutricionais.

Segundo [8] destaca que o leite de búfala mostra-se superior ao leite de vaca em relação à qualidade devido a seus teores de cálcio, gorduras, proteínas e minerais. Além disso, é mais concentrado, o que beneficia as indústrias proporcionando ótimo rendimento. Para que seja produzido queijo de qualidade é necessário ter matéria-prima também de qualidade, no caso o leite, que deve ser produzido seguindo as normas de higiene e manejo, mantendo a higienização em todos os processos.

Segundo [9] o queijo tipo mozarela tem sua origem na Itália e, no Brasil a mozarela de búfala é o produto que mais faz o país se expandir neste ramo devido a sua demanda. Pelo fato de possuir características e sabor peculiares estão conquistando o consumidor, que reconhece seu diferencial. A procura por este tipo de alimento faz com que os produtores de leite de búfala sintam-se incentivados a investirem em seus negócios, e com seus produtos valorizados tem como resultado a compensação pela agroindústria para fornecimento de sua matéria-prima com preços superiores ao preço pago pelo leite bovino.

A composição e qualidade do leite de búfala são fatores que contribuem para o crescimento do setor no mercado, pois segundo [10] o rendimento do leite bubalino para a produção do queijo é maior que o leite bovino devido ao elevado teor de matéria seca na composição, visto que para produzir $1 \mathrm{~kg}$ de queijo de búfala são necessários 8 litros de leite, já para a produção do queijo de vaca são necessários 12 litros. Pode-se observar a diferença de ambos visualmente onde o leite de búfala é totalmente branco enquanto o de vaca é amarelo. Na figura abaixo se encontra a composição de ambos os leites.

Tabela 1 - Comparação entre leite de búfala e de vaca.

\begin{tabular}{|c|c|c|}
\hline $\begin{array}{l}\text { COMPONENTES } \\
\text { DO LEITE }\end{array}$ & BÙFALA & BOVINA \\
\hline Proteínas & $4,00 \%$ & $3,50 \%$ \\
\hline Lipídios & $8,00 \%$ & $3,50 \%$ \\
\hline Lactose & $4,90 \%$ & $4,70 \%$ \\
\hline Água & $82,00 \%$ & $87,80 \%$ \\
\hline Colesterol Total & $214 \mathrm{mg} \%$ & $319 \mathrm{mg} \%$ \\
\hline
\end{tabular}

Fonte: [1].

\section{II.3 GESTÃO DA PRODUÇÃO E A FILOSOFIA ENXUTA}

“Gestão da Produção é a atividade de gerenciamento de recursos escassos e processos que produzem e entregam bens e serviços, visando a atender as necessidades e/ou desejos de qualidade, tempo e custo de seus clientes". [11].

Segundo [11], a Gestão da Produção ou Administração da Produção consiste em atividades necessárias para a produção de bens e serviços. A partir dessa gestão e com o avanço e desenvolvimento de novas tecnologias surgiram novos conceitos a ser seguido pelas organizações, que envolvem padronização de produtos e processos, planejar e controlar a produção, treinar os 
funcionários para se obter mão-de-obra qualificada para as tarefas a serem realizadas, controle das finanças, desenvolvimento de gestores e supervisores e de técnicas de vendas.

Para [12] a gestão pode ser desenvolvida com tais funções:

Planejamento: a empresa deve ter possibilidades de ação para atingir seus objetivos, para isso se faz necessário uma avaliação de quais meios existem na empresa para pôr em prática tais possibilidades;

Execução e Controle: etapa que surgem os problemas, erros do processo, e fica sob a responsabilidade do operador a constatação e correção de tais falhas. Os métodos de correção devem ser conhecidos por todos os envolvidos para que se mantenha a qualidade no processo;

Monitoramento: realizado através de inspeção na fonte, ações preventivas e corretivas e melhoria contínua.

No meio a tantos desperdícios, as empresas têm buscado cada vez mais em realizar a gestão da produção de forma enxuta por meio de processos que sejam simples para os empresários e que apresente viabilidade para serem colocados em práticas. Dessa forma, analisar um processo sob um ponto de vista enxuto se torna cada vez mais essencial para os planejadores que a redução de lead time nos processos bem como a redução de custos.

De acordo com [13] uma abordagem enxuta de gerenciar operações é fundamentada em fazer bem as coisas simples, em fazê-las cada vez melhor e (acima de tudo) em eliminar todos os desperdícios em cada passo do processo.

A filosofia da produção enxuta possui basicamente três pilares, a saber [13]:

- Eliminar desperdícios

- Envolver todos

- Melhoramento contínuo

Agregando todos esses pilares nos processos de gestão da produção, viabiliza as operações nas organizações a alcançarem patamares elevados de produtividade visando à utilização máxima dos recursos.

\section{II.4 MAPEAMENTO DE PROCESSOS}

Segundo [13] o mapeamento de processos é entendido como um conjunto de atividades pertencentes a um processo, expressando como elas se relacionam entre si. [14] relata que podem ser construídos representações gráficas dos processos através do mapeamento dos mesmos, facilitando a identificação e entendimento das etapas e fluxos de atividades, garante uma vasta visão do processo contribuindo para a implementação de melhorias. [15] complementam dizendo que essas representações gráficas podem ser mapas, fluxos ou diagramas de processos que seja de fácil compreensão e bem objetivo para que sejam entendidos por todos os envolvidos, independentemente de sua capacitação.

Para [16], quando o mapeamento é empregado de forma correta, pode-se documentar todos os elementos que fazem parte do processo, fazendo a correção daqueles que estejam apontando problemas, e por fim podendo identificar as atividades que não agregam valor. Conforme [17] após a realização do mapeamento de processos é o momento de identificar as falhas presentes e propor melhorias, estabelecendo prazos para as implantações, levando em conta a disponibilidade dos recursos necessários.

\section{METODOLOGIA DA PESQUISA}

Serão apresentados os dados referentes ao processo produtivo de queijo de búfala e também o passo a passo de suas atividades por meio do mapeamento de processos, utilizando-se o diagrama de processos proposto em [13].
A pesquisa define-se como um estudo de caso, pois segundo [2] é considerado como um esforço em que se buscam informações detalhadas sobre o objeto de estudo, para que possa ter um conhecimento amplo sobre o mesmo, e isso só é possível com o estudo de caso, pois se torna uma incapacidade dos outros métodos de busca.

Para atender aos objetivos deste artigo foi utilizada a pesquisa exploratória que, segundo [2],o objetivo é propiciar maior proximidade com o problema, para que se possa ter mais compreensão sobre o mesmo. Essas pesquisas envolvem o levantamento bibliográfico sobre o assunto, entrevistas com pessoas que vivenciam a situação estudada, bem como o reconhecimento de situações que possam ser exemplos que levem sua compreensão.

Quanto aos procedimentos utilizados para a realização da pesquisa, utilizou-se a pesquisa de campo que, segundo [3], definese pelo estudo extenso onde se realizam coleta de dados diretamente através das pessoas envolvidas no caso, além de realizar a pesquisa bibliográfica ou documental. Para a coleta de informações foram realizadas entrevistas, questionários e observação participante.

Em relação à abordagem, o artigo expressa-se como qualitativo e quantitativo ao mesmo tempo, o chamado qualiquanti. De acordo com [4], o método qualitativo é aquele que leva em conta fatores de julgamento e intuição, ou seja, questões mais particulares, no momento de analisar os dados. Já o método quantitativo é baseado em dados históricos, onde são realizadas análises de conduta para que esses possam ser projetados para o futuro.

\section{RESULTADOS}

\section{IV.1 MAPEAMENTO DO PROCESSO ATUAL DA EMPRESA}

O processo de produção de queijo está voltado para a fabricação do produto, que tem como principal matéria - prima o leite de búfala, sendo essa matéria - prima própria da empresa e, demais ingredientes utilizados no processo produtivo como sal e coagulante e também as embalagens e equipamentos (utensílios para manuseio e preparo) são adquiridos de fornecedores. Na figura 1, é demonstrado o mapeamento do processo atual da empresa através do diagrama de processos, no qual são apresentados os tempos e a descrição dos passos para cada fase do processo produtivo de queijo de búfala.

Figura 1 - Diagramação do processo produtivo do queijo de búfala.
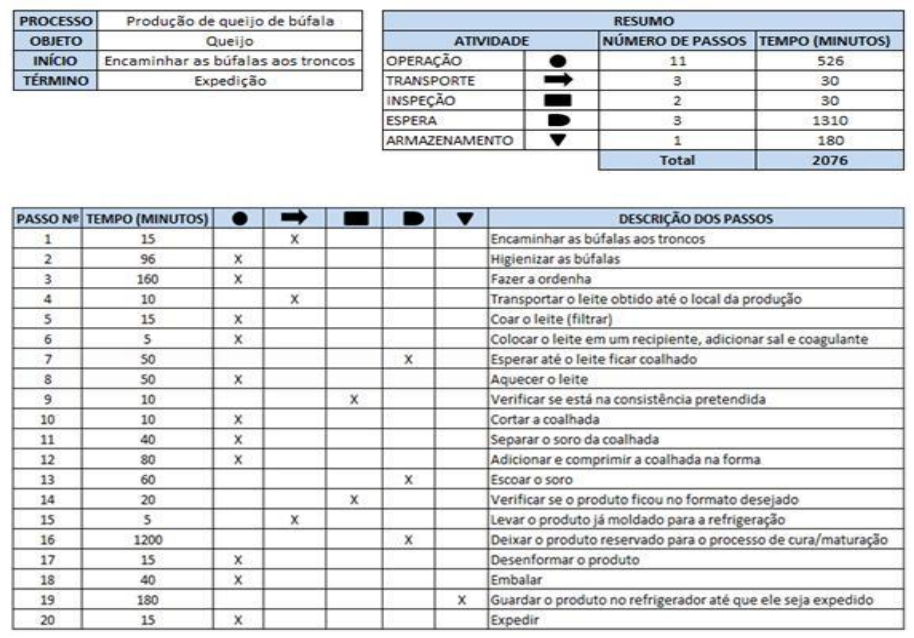

Fonte: Autor, (2019). 
Conforme exposto na Figura 1, o processo produtivo do queijo ocorre por meio das seguintes atividades:

- Encaminhar as búfalas aos troncos: as búfalas são trazidas do pasto e encaminhadas ao tronco (estrutura estreita de madeira para limitar os movimentos das búfalas). O tempo total dessa atividade é de 15 minutos.

- Realização da higiene das búfalas: é utilizada água de boa procedência misturada a uma quantidade de cloro para a lavagem dos tetos das búfalas, logo após os tetos são secos com papel toalha. Esse processo leva em torno de 3 minutos por búfala. Como a fazenda conta com 32 búfalas, o tempo total desse processo é de 96 minutos.

- Ordenha: para o controle da qualidade do leite são despejados os quatro primeiros jatos de leite em uma caneca de fundo escuro para a análise da cor e textura do leite, se tiver alguma irregularidade, é cancelada a ordenha daquele animal. A ordenha é feita com o auxílio de uma ordenhadeira mecânica. Esse processo leva aproximadamente 5 minutos por búfala, e é feito por meio de fila indiana. O tempo total para a ordenha das 32 búfalas é de 160 minutos. A ordenha é feita apenas com a ordenhadeira mecânica para que o leite não tenha nenhum contato com o meio externo, evitando contaminações e garantindo a integridade do mesmo.

- Transporte do leite até o local da produção: logo após a ordenha o leite é transportado em galões específicos até o local de produção. A duração desse processo é de 10 minutos.

- Coar o leite: assim que o leite chega ao local de produção é coado com um utensílio próprio para essa tarefa. Sua duração é em torno de 15 minutos.

- Adição de coagulante e sal ao leite: após a tarefa anterior, são adicionados o coagulante e o sal ao leite, levando aproximadamente 5 minutos para misturar bem esses ingredientes.

- Processo de coagulação: tempo de espera até o leite ficar coalhado, tendo duração de 50minutos.

- Aquecimento do leite: quando a coalhada atinge seu ponto ideal ela é levada ao fogão a lenha e aquecida por 5 minutos. O aquecimento é feito de 10 em 10 litros. A produção diária é de 100 litros, portanto o processo é repetido por 10 vezes e o tempo total gasto é de 50 minutos.

- Verificar se está na consistência pretendida: esta etapa tem duração de 10 minutos.

- Corte da coalhada e separação do soro: após o leite aquecido é feito o corte da coalhada e separação do soro, visto que quando o leite é aquecido o soro sobe até a superfície do caldeirão e a coalhada fica em baixo facilitando essa separação. Esse processo dura aproximadamente 10 minutos para os 100 litros.

- Adicionar e comprimir a coalhada na forma: processo em que a coalhada ganha formato. Em uma forma redonda é adicionada e comprimida a coalha até ficar homogênea. Esse processo dura 4 minutos por queijo. Como são produzidos 20 queijos diariamente o tempo total é de 80 minutos.

- Escoar o soro: após o processo descrito anteriormente, é aguardada 1 hora até escorrer todo o soro.

- Verificar se o produto ficou no formato desejado: Sua duração é de 20 minutos, tempo esse que inclui a inspeção dos 20 queijos (quantidade diária produzida).

- Refrigerar o produto já moldado: logo que todo o soro tiver escoado, o queijo é refrigerado sem tirar a forma em que foi produzido. Ele é refrigerado por 20 horas.

- Desenformar: após o produto ser retirado do freezer inicia-se o processo de retirada da forma. O tempo gasto com esse processo é de 15 minutos para os 20 queijos (quantidade diária produzida).

- Embalar: o queijo é embalado com embalagem de plástico. A duração desse processo é 2 minutos por queijo, totalizando 40 minutos para todos os queijos.

- Estocar: depois de tudo pronto o queijo é acondicionado no refrigerador até a chegada dos compradores.

- Expedir: a expedição acontece quando o cliente vai até a empresa e faz seu pedido.

\section{IV.2 REDESENHO DO MAPEAMENTO DO PROCESSO}

Com a análise do processo, foram identificadas atividades que poderiam ser substituídas, unificadas e melhoradas. Os ganhos obtidos através da sugestão do novo mapeamento de processos para a empresa estudada foram à redução do tempo de ciclo do processo e sugestão de mudanças de atividades.

As mudanças identificadas referem-se à unificação do passo 1 e 2 que consistem em levar as búfalas para os troncos (com duração de 15 minutos) e fazer a higienização das mesmas (processo é realizado manualmente em uma búfala de cada vez, onde o trabalhador com o auxílio de um balde com água e cloro, utilizando luva nas mãos, lava os tetos das búfalas e depois seca com papel toalha, tendo duração de 3 minutos por búfala, totalizando, assim, 96 minutos). Com a sugestão do redesenho do mapeamento esses dois passos, passam a ser somente encaminhar as búfalas para o processo de higienização, tendo duração de 15 minutos para serem levadas ao local e mais 11 minutos para serem higienizadas e, ao invés de o processo ocorrer manualmente ele passa a ser automatizado: sugere-se que seja instalado um sistema de lavagem em que as búfalas vão ser higienizadas através da água com cloro proveniente de uma caixa d'água, que fará a distribuição da mesma através de "chuveirinhos" dispostos no chão que irão borrifar essa água atingindo os tetos dos animais, com isso, o espaço vai acomodar três búfalas por vez e higienizá-las em 1 minuto. O custo para essa instalação será de aproximadamente R $\$$ 320,00 , considerando gastos com a compra de uma caixa d'água, canos de PVC, duchas, acessórios necessários e instalação, visto que não será contabilizado o valor gasto com água nem energia elétrica para higienização, pois a fazenda conta com poço artesiano, ficando isento de qualquer taxa e o funcionamento do novo sistema ocorre movido por pressão.

O passo 8 que consiste em aquecer o leite e tem duração de 50 minutos, pois ele é aquecido a cada dez litros devido a capacidade da panela, faz-se a sugestão da compra de mais uma panela com a mesma capacidade (o fogão a lenha utilizado suporta duas panelas), para assim aquecer 20 litros de leite por vez, reduzindo o tempo dessa atividade pela metade. O custo para a aquisição da panela é de $\mathrm{R} \$ 80,00$.

O passo 17 e 18 foi unificado, agora o produto é desenformado e já embalado, sem precisar desenformar todos eles para depois seguir para a etapa de embalagem. Desenformando e já colocando diretamente na embalagem é possível reduzir o tempo da operação em 20 min.

Na figura 2 há o redesenho do mapeamento proposto para o processo: 

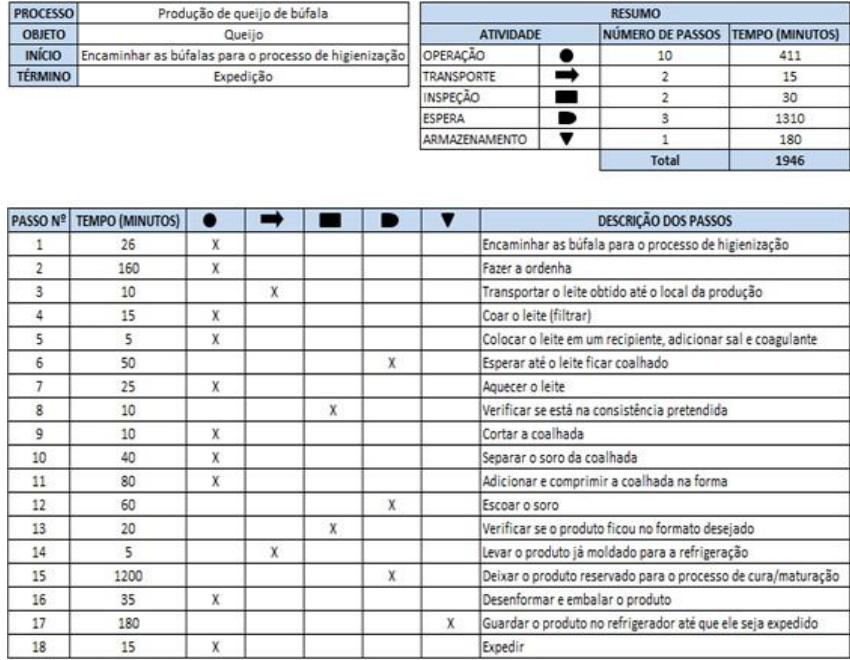

Figura 2 - Redesenho do diagrama do processo de queijo de búfala.

Fonte: Autores, (2019).

\section{IV.3 IMPACTO DAS MUDANÇAS SUGERIDAS NO REDESENHO DO PROCESSO}

Esta seção busca realizar um comparativo entre o impacto que ocorreu no processo antes e depois da proposta de redesenho.

O principal impacto diz respeito ao Lead Time. Antes o processo possuía uma diversidade de atividades que não agregavam valor, e com as sugestões de mudança, foi possível obter ganhos, na forma de redução do tempo total de atravessamento do processo.

A tabela a seguir faz uma síntese dos principais ganhos associados ao tempo.

Tabela 2 - Comparação das mudanças sugeridas e impactos no Lead Time do processo.

\begin{tabular}{|c|c|c|c|}
\hline Mudança & $\begin{array}{c}\text { Tempo } \\
\text { antes do } \\
\text { redesenho }\end{array}$ & $\begin{array}{c}\text { Tempo } \\
\text { após o } \\
\text { redesenho }\end{array}$ & $\begin{array}{c}\text { Ganho de } \\
\text { tempo no } \\
\text { processo }\end{array}$ \\
\hline $\begin{array}{c}\text { Unificação dos } \\
\text { passos 1 e 2 }\end{array}$ & 111 minutos & 26 minutos & 85 minutos \\
\hline Passo 8 & 50 minutos & 25 minutos & 25 minutos \\
\hline $\begin{array}{c}\text { Unificação dos } \\
\text { passos 17 e 18 }\end{array}$ & 55 minutos & 35 minutos & 20 minutos \\
\hline Total & & $\begin{array}{c}130 \\
\text { minutos }\end{array}$ \\
\hline
\end{tabular}

Fonte: Autores.

De acordo com a tabela 2, é possível observar que houve um ganho de tempo de 85 minutos com a primeira mudança, um ganho de 25 minutos com a segunda mudança e um ganho de 20 minutos com a terceira mudança.

A primeira mudança esta relacionada com a unificação dos passos 1 e 2, ou seja, que consistem em levar as búfalas para os troncos (com duração antiga duração de 15 minutos) e fazer a higienização das mesmas (com antiga duração de 96 minutos). Com a sugestão do redesenho do mapeamento esses dois passos, passam a ser somente encaminhar as búfalas para o processo de higienização, tendo duração de 15 minutos para serem levadas ao local e mais 11 minutos para serem higienizadas e, ao invés de o processo ocorrer manualmente ele passa a ser automatizado via aquisição de máquinas de lavagens adequadas descritas na seção anterior, com um custo de aproximadamente $\mathrm{R} \$ 320,00$.

A segunda mudança está relacionada com o passo 8, que se refere ao aquecimento do leite. Com a aquisição de uma panela com maior capacidade, será possível aquecer uma quantidade de 20 litros por vez, reduzindo assim o tempo desta atividade pela metade. Com isso, é possível notas um ganho de 25 minutos. O custo associado com a aquisição de aproximadamente $\mathrm{R} \$ 80,00$.

A ultima mudança refere-se à unificação dos passos 17 e 18, que consiste em desenformar o produto e embalar, que gastavam 15 e 40 minutos, respectivamente. Nota-se que agora o produto será desenformado e já embalado, sem a necessidade de desenformar previamente para seguir para a etapa de embalagem. Essa mudança permite um ganho de 20 minutos no processo total.

Portanto, com as mudanças sugeridas é possível obter a redução do lead time do processo, como dito anteriormente, e de uma maneira geral poder aplicar técnicas enxutas na eliminação de tempos que não agregam valor. Foram diminuídos dois passos do processo e há um ganho de 130 minutos no total, o custo gerado com as adaptações para as mudanças sugeridas pode chegar a, aproximadamente, $\mathrm{R} \$ 400,00$, mas a longo prazo é viável para a empresa.

\section{CONSIDERAÇÕES FINAIS}

A busca crescente por práticas de manufatura enxuta nas organizações tem se tornado uma questão primordial para a sobrevivência das empresas no mercado atual. Dessa forma, esse trabalho aplicou uma ferramenta clássica de manufatura enxuta com a finalidade de proporcionar uma visão sistêmica do processo com vista na eliminação de desperdícios ao longo dos processos.

A partir da análise sobre o processo produtivo realizado em uma empresa artesanal de produção de queijo de búfala, buscou-se propor melhorias através de uma ferramenta de manufatura enxuta chamada: mapeamento dos processos. Através de um diagrama de processos foi possível observar o tempo de execução de cada atividade, esta ferramenta possibilitou a identificação de gargalos, atividades passíveis de unificação e melhorias. Após o levantamento dos da dose das possíveis correções, foi possível traçar um plano de melhoria através da aplicação de correções que proporcionam a redução de tempo e um desenvolvimento de processos mais eficientes e eficazes. $\mathrm{O}$ redesenho do processo proporciona a redução de 130 minutos de mão de obra para execução de atividades.

Com isso, através do novo mapeamento de processo se obtém a redução lead time eliminando assim atividades que não agregam valor para o processo, conquistada através da unificação de atividades e propostas de melhorias apresentadas.

\section{REFERÊNCIAS}

[1] ABCB. Associação Brasileira de Criadores de Búfalos, São Paulo, 2018.

Disponível

em:<http://www.bufalo.com.br/abcb.html > Acesso $12 / 10 / 2018$.

[2] GIL, A. C. Como elaborar projetos de pesquisa. 4. ed. São Paulo: Atlas, 2007.

[3] Fonseca, J. J. S. Metodologia da pesquisa científica. Fortaleza: UEC, 2002. Apostila.

[4] CORRÊA, H.L.; CORRÊA, C, A. Administração de Produção e Operações. São Paulo: Atlas S.A, 2009.

[5] Bernardes, O. Bubalinocultura no Brasil: situação e importância econômica. Revista Brasileira de Reprodução Animal, Belo 
Horizonte, v.31, n.3, p.293 - 298. jul./set. 2007. Disponível em: <www.cbra.org.br>Acesso em: 12/10/2018.

[6]Ministério da Agricultura, Pecuária e abastecimento. Dados do rebanho bovino e bubalino no Brāsil - 2017. Disponível em:<www.agricultura.gov.br/.../Dadosderebanhobovinoebubalin odoBrasil_2017.pdf>Acesso em: 12/10/2018.

[7]Teixeira, L. V., et. al. Leite de búfala na indústria de produtos lácteos. Revista Brasileira de Reprodução Animal, Belo Horizonte, v.29, n.2, p.96-100, abr./jun.2005. Disponível em: <www.cbra.org.br>Acesso em: 26/02/2018.

[8] Kirchner, B. L. Produção de muzzarella de búfala. Paraná, 2006. 73 f. Monografia (Graduação em Medicina Veterinária) Universidade Tuiuti do Paraná, Curitiba-PR, 2006.

[9] Rosales, F. P. Competitividade do complexo agroindustrial do leite de búfala no estado de São Paulo. São Paulo, 2013. 171 f. Dissertação (Mestrado em Engenharia de Produção) Universidade Federal de São Carlos, São Paulo, 2013.

[10] Canali, A. C. Análise de viabilidade econômico- financeira de uma distribuidora de produtos de origem bubalina. Rio Grande do Sul, 2011. 71f. Monografia (Bacharel em administração) Universidade Federal do Rio Grande do Sul, Rio Grande do Sul, 2011.

[11] Pasqualini, F., et. al. Gestão da Produção. Rio Grande do Sul: Ed. Unijuí, 2010. 100 p. (Coleção educação à distância. Série livrotexto).

[12] SEBRAE. A gestão de produção é essencial para sua empresa crescer. 2015.2 Disponível em: <http://www.sebrae.com.br/sites/PortalSebrae/artigos/a-gestaode-producao-e-essencial-para-a-sua-empresa-crescer $>$ Acesso em: 24/10/2018.

[13] SLACK, N., et. al. Administração da Produção. $3^{\text {a }}$ Ed. São Paulo: Atlas, 2009.

[14]CURY, Antonio. Organização e Métodos: Uma Visão Holística. 8 Ed. rev. e ampl. 5. reimpr. São Paulo: Atlas, 2010.

[15] Pavani Júnior, Orlando; Scucuglia, Rafael. Mapeamento e gestão por processos: BPM (Business Process Management). São Paulo: M. Books, 2011.

[16] de Melo, A. E. N. S. Aplicação do Mapeamento de Processo e da simulação no desenvolvimento de projetos de processos produtivos. Itajubá: UNIFEI, 2011.

[17] Orofino, Antonio Carlos. Processos com resultados: a busca da melhoria continuada. Rio de Janeiro: LTC, 2009. 